\title{
Effect of UV Laser Conditioning on the Structure of KDP Crystal
}

\author{
Decheng Guo,, ${ }^{1,2}$ Xiaodong Jiang, ${ }^{1}$ Jing Huang, ${ }^{1}$ Fengrui Wang, \\ Hongjie Liu, ${ }^{1}$ and Xiaotao $\mathrm{Zu}^{2}$ \\ ${ }^{1}$ Research Center of Laser Fusion, China Academy of Engineering Physics, Mianyang 621900, China \\ ${ }^{2}$ School of Physical Electronics, University of Electronic Science and Technology of China, Chengdu 610054, China \\ Correspondence should be addressed to Xiaodong Jiang; jiangxdong@163.com
}

Received 17 March 2014; Accepted 3 June 2014; Published 18 June 2014

Academic Editor: Wanguo Zheng

Copyright (C) 2014 Decheng Guo et al. This is an open access article distributed under the Creative Commons Attribution License, which permits unrestricted use, distribution, and reproduction in any medium, provided the original work is properly cited.

\begin{abstract}
Multiparametric raster scanning experiments for KDP crystals are carried out to study the laser conditioning efficiency as a function of laser fluence, fluence step, and pulse sequence by using ultraviolet (UV) laser irradiation with pulse duration of approximately $7 \mathrm{~ns}$. It indicates that damage resistance of KDP can be enhanced after conditioning process. And laser conditioning efficiency depends on the maximal fluence which is below the damage threshold. Raman spectra and photothermal absorption have also been studied on KDP crystals before and after multiparametric laser conditioning. Photothermal absorption data reveal that absorbance of conditioned KDP crystal decreases with the increase of laser fluence and the damage threshold of low absorption area is higher. Raman analysis reveals that the effectiveness of laser conditioning relies mainly on the individual mode of $\mathrm{PO}_{4}$ molecule.
\end{abstract}

\section{Introduction}

Potassium dihydrogen phosphate (KDP), with good physical properties including large nonlinear optical coefficient, good structural quality, and mechanical properties, is used in many large-aperture laser systems as frequency conversion crystal and electrooptic switching. However, its maximal fluence remains a significant limitation in high power laser project [1]. In order to increase the laser induced damage threshold (LIDT), two confirmed treatments for improving laser resistibility have been demonstrated, including thermal annealing $[2,3]$ and laser conditioning $[4,5]$. Laser conditioning is the reliable mitigation method, which gives the most convincing results $[6,7]$. Laser conditioning efficiency is largely determined by the preexposure laser parameters, such as laser fluence, wavelength, pulse number, and length $[8,9]$. For instance, Negres et al. reported the effectiveness of laser conditioning with $355 \mathrm{~nm}, 2.5 \mathrm{~ns}$ laser pulses with increasing fluence in deuterated potassium dihydrogen phosphate (DKDP) crystals as a function of fluence step and number of pulses per step. Their results demonstrate that a key laser parameter in achieving the best damage performance at $355 \mathrm{~nm}$ is the maximal fluence and that this parameter is material dependent [4]. DeMange et al. investigated the damage behavior of KDP and DKDP crystals under $1064 \mathrm{~nm}, 532 \mathrm{~nm}$, and $355 \mathrm{~nm}$ irradiation subsequent to laser conditioning. Their results reveal that the level of conditioning is strongly dependent on the conditioning wavelength [10].

The mechanisms of laser conditioning are still not well understood, although there is a strong implication that the interaction of intrinsic and/or extrinsic defects with subdamage laser fluence plays a key role [11-13]. In order to understand this, most research using nondestructive techniques is performed such as Raman spectrum and optical absorption. These techniques give information on the physical and chemical nature of the defects. Marshall and coworkers described that the $266 \mathrm{~nm}$ light causes a broad absorption band at $300 \mathrm{~nm}-650 \mathrm{~nm}$ via two-photo absorption [14]. Woods et al. observed a weak correlation between the scattering centers and the initiation sites of damage [15]. Damiani et al. [16] investigated the KDP with different nondestructive optical diagnostics during the conditioning using an excimer laser at $351 \mathrm{~nm}$. They demonstrated a correlation between the optical signal intensity and the laser induced damage thresholds (LIDT). But there are few reports about structural changes for KDP crystals during the raster scanning conditioning process. 


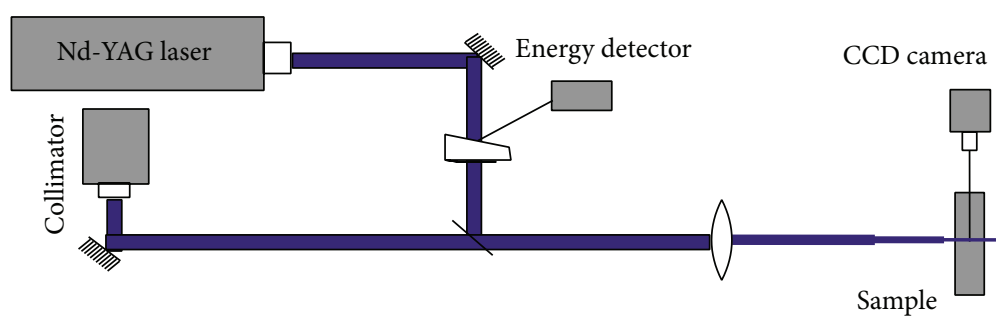

FIgURE 1: Optical layout of laser conditioning and damage test experiment.

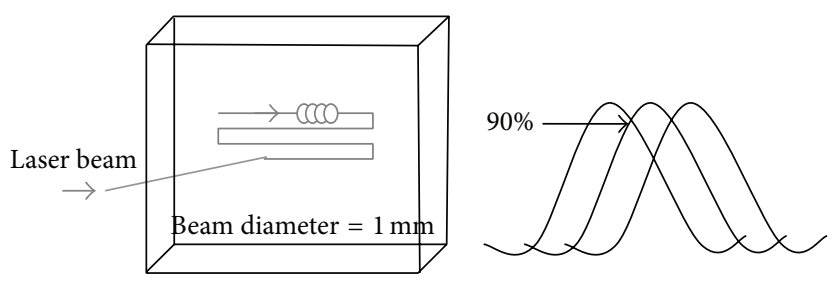

FIGURE 2: Schematic of scan-conditioning on a crystal.

In this paper, we attempt to use a nondestructive optical analysis approach by studying the effect of scan-conditioning via using an Nd-YAG laser at $355 \mathrm{~nm}$ with different laser parameters. Structural modification for KDP after irradiation was characterized by using Raman spectra and photothermal absorption. The correlations between the spectral information and conditioning effect are discussed. This work aims to obtain a better knowledge of the laser conditioning mechanism.

\section{Experimental Set-Up and Procedure}

2.1. The Scan Layout. The experimental layout is drawn in Figure 1. The laser source is an Nd-YAG laser operating at $355 \mathrm{~nm}$. The laser has a Gaussian temporal profile with pulse duration of about $7 \mathrm{~ns}$. The maximum energy is $200 \mathrm{~mJ}$, and the maximum repetition rate is $10 \mathrm{~Hz}$. The KDP sample was cut to $50 \times 50 \times 5 \mathrm{~mm}^{3}$ size plate and positioned in the laser beam with a three-dimensional motorized stage. A CCD acts as a scattering diagnostic to capture the image of bulk damage orthogonally to the direction of laser propagation, through the side of the sample.

For the conditioning experiments the sample was scanned continuously along the $x$-axis and then stopped along the $y$-axis at the end of each scan as shown in Figure 2. The diameter between two adjacent spots is the diameter determined from the $90 \%$-of-peak-fluence beam.

2.2. Experimental Procedure. We measured the crystal by two different methods before and after laser conditioning. Photothermal measurement was performed with photothermal common-path interferometer by using a $2.0 \sim 2.5 \mathrm{~mW}$ $\mathrm{He}-\mathrm{Ne}$ laser at $632.8 \mathrm{~nm}$ as probe light under the Nd-YAG laser excitation at $355 \mathrm{~nm}$. The principle is to measure the absorption of the material with a photothermal effect. Light energy absorbed and not lost by subsequent emission results in sample heating. This heating results in a temperature change and changes in thermodynamic parameters of the sample which are related to temperature. Measurements of the temperature, pressure, or density changes that occur due to optical absorption are ultimately the basis for the photothermal spectroscopic methods; Raman spectra measurement was performed with a Nicolet Raman 950 spectrometer by using a $1064 \mathrm{~nm}$ laser as excitation source with a power of $4 \mathrm{~mW}$ at room temperature.

For the experiments, the KDP crystal was separated into four different areas of $20 \times 20 \mathrm{~mm}^{2}$. One squared area is a pristine region. The other three areas are exposed to the conditioning pulse with subdamage threshold fluence.

\section{Results and Analysis}

3.1. Performance of Laser Conditioning. The dependence of conditioning efficiency on preexposure laser parameters was measured by using R/1 scanning mode. Pristine KDP crystals were exposed first to the conditioning pulse at different parameters including fluence, pulse number, and fluence step. And then the bulk damage probability test was measured by 1/1 mode; the results were shown in Figures 3(a), 3(b), and $3(c)$ separately. The samples were scanned at different ramped fluence procedures: $0.77-1.84-2.82 \mathrm{~J} / \mathrm{cm}^{2}, 0.77-1.84-2.82-$ $3.77 \mathrm{~J} / \mathrm{cm}^{2}$, and $0.77-1.84-2.82-3.77-4.59 \mathrm{~J} / \mathrm{cm}^{2}$ which are called three-fluence, four-fluence, and five-fluence scanning, respectively. As shown in Figure 3(a), the damage threshold increases with increasing preexposure pulse fluence starting from the lowest tested three-fluence scanning after rasterconditioning. The damage probability fluence for the fourfluence scanning is $\sim 1.22 \mathrm{X}$ higher than that of three-fluence scanning. And that for five-fluence scanning is $\sim 1.18 \mathrm{X}$ higher than that of four-fluence scanning. So it is clear that the higher laser fluence enhances the damage resistance further.

As shown in Figure 3(b), the damage probability fluence with three pulses is $1.1 \mathrm{X}$ higher than that with two pulses (the preexposure fluence is $4.59 \mathrm{~J} / \mathrm{cm}^{2}$ ). But the damage 


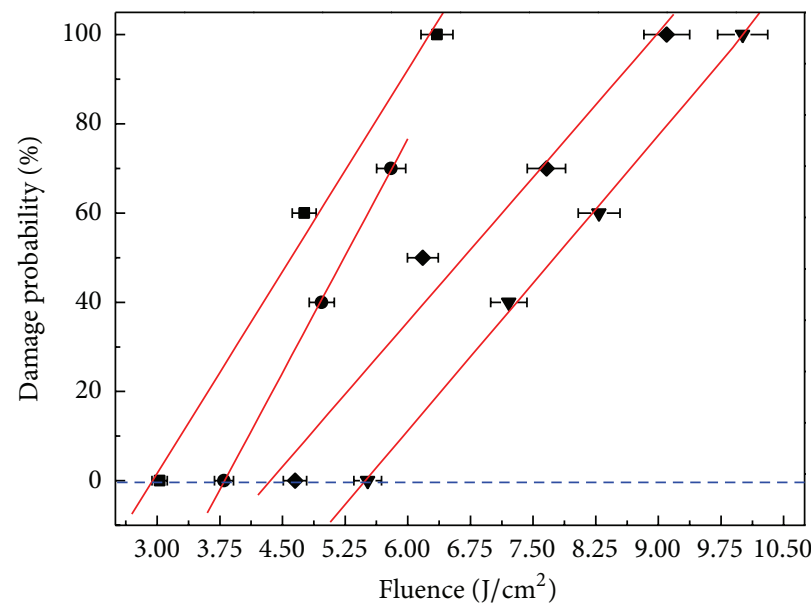

Pre-exposure fluence - Unconditioning - $0.77-1.84-2.82 \mathrm{~J} / \mathrm{cm}^{2}$
- $0.77-1.84-2.82-3.77 \mathrm{~J} / \mathrm{cm}^{2}$

$0.77-1.84-2.82-3.77-4.59 \mathrm{~J} / \mathrm{cm}^{2}$

(a)

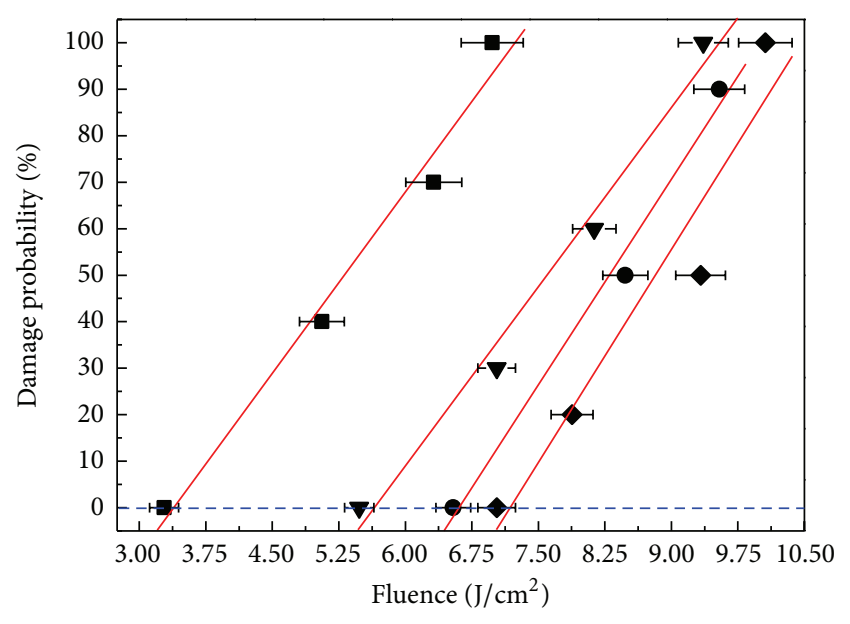

Preexposure scan number (fluence is $0.77-1.84-2.82-3.77-4.59 \mathrm{~J} / \mathrm{cm}^{2}$ )

- Unconditioning

- 2 pulses $\checkmark 4$ pulses

(b)

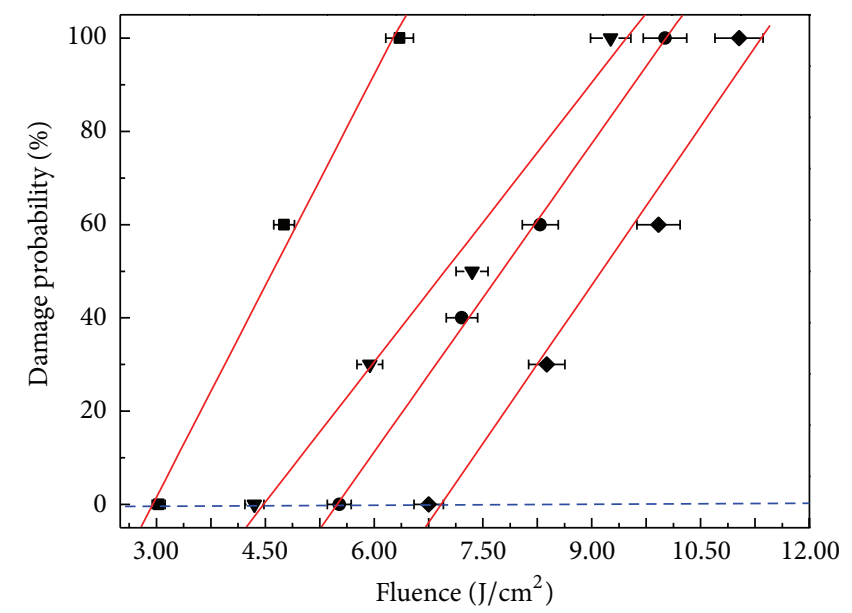

Preexposure fluence step

- Unconditioning

$0.77-2.26-3.77-4.59 \mathrm{~J} / \mathrm{cm}^{2}$

- $0.77-1.84-2.82-3.77-4.59 \mathrm{~J} / \mathrm{cm}^{2}$

- $0.77-2.59-4.59 \mathrm{~J} / \mathrm{cm}^{2}$

(c)

FIGURE 3: Results of 1-on-1 damage testing of R-on-1 scan-conditioned KDP crystals with multiparametric conditions: (a) laser fluence; (b) pulse number; (c) fluence step. Light gray lines were fitted linear.

probability fluence with four pulses is smaller than that with two and three pulses. Therefore, this result indicates that an appropriate quantity of scanning pulses can improve the effect of conditioning, but too many pulses may decrease the conditioning efficiency.

As shown in Figure 3(c), the damage probability fluence with two fluence steps (ramping fluence interval is about $\left.1.5 \mathrm{~J} / \mathrm{cm}^{2}\right)$ is $1.2 \mathrm{X}$ higher than that with one fluence step (ramping fluence interval is about $1 \mathrm{~J} / \mathrm{cm}^{2}$ ). And the result of three fluence steps (ramping fluence interval is about $2 \mathrm{~J} / \mathrm{cm}^{2}$ ) is smaller than the others. Consequently, this result indicated that an appropriate level of scanning steps can improve the effect of conditioning, but too big steps may decrease the conditioning efficiency.

As shown in Figure 3, the laser conditioning with subdamage threshold fluence can improve the laser damage resistance capability of KDP crystals. The laser conditioning efficiency increases with increase in preexposure pulse fluence, while an appropriate quantity of scanning pulses and steps can enhance the conditioning efficiency further. In other words, the effectiveness of laser conditioning relies mainly on the maximal conditioning fluence. For this case, the possible explanation is that the first conditioning pulse with the lower fluence only passivizes the biggest defect clusters. 
And with the increase of laser fluence, smaller and smaller clusters are treated [17]. For the process of multiple-pulses conditioning, it may be understood with defect absorber model. Under the irradiation of successive laser pulses, defect absorber and surrounding material are easy to be heated up to decomposition temperature due to the energy accumulation [11]. Therefore, the appropriate number of pulses can increase the effectiveness of laser conditioning. The energy cumulative effect can also explain the influence of fluence step on the laser conditioning efficiency. However, some other changes occur in surrounding material or absorber itself due to thermochemical and mechanochemical process before being heated up to decomposition temperature. That is why the appropriate fluence step can increase the damage resistance rather than the maximum fluence.

3.2. Photothermal Absorption. Absorption coefficient of the $\mathrm{KDP}$ crystal is measured with a photothermal common-path interferometer which is based on a consistent interference approach to the optical detection. Three areas are scanned. The result is displayed in Figure 4. The absorption coefficient after raster-conditioning decreases with the increasing in preexposure pulse fluence.

In order to understand the correlation between the absorption and laser induced damage, the damage threshold of two different areas measured by 1-on-1 mode is given in Figure 5. Apparently, the area of the low absorption value has the high damage resistance. For this area, laser pulse with $7 \mathrm{~J} / \mathrm{cm}^{2}$ cannot raise the damage incident. At $9.3 \mathrm{~J} / \mathrm{cm}^{2}$ the damage probability is $50 \%$. For the area with strong absorption, the probability increases to $90 \%$ at $9.3 \mathrm{~J} / \mathrm{cm}^{2}$. Consequently, it intimates that the initial damage may be correlated with the absorption due to changing of various defects in bulk KDP crystal. Further, in the laser conditioning process, various types of defects which exist in crystal are treated. The precursor defects may be annihilated due to the thermally activated migration or induced phase transition and a subsequent crystalline rearrangement by high temperature. As a consequence, some defect absorption vanishes [18]. Therefore, damage resistibility of low absorption area is higher than that of strong absorption area.

3.3. Raman Spectroscopy. Figure 6 shows Raman spectra of $\mathrm{KDP}$ at room temperature before and after laser conditioning. Spectral data and proposed assignment, which are in good accordance with the results of Serra et al. [19] and Agrawal and Perry [20], were described in Table 1. The Raman active modes belong to the A1, B1, B2, and E representations of the factor group $\mathrm{D}_{2 \mathrm{~d}}$. Modes belonging to the $\mathrm{B}$ and $\mathrm{E}$ representations are simultaneously Raman and infrared active. According to Som et al., the peak observed at $114 \mathrm{~cm}^{-1}$ may be assigned to $\mathrm{K}-\mathrm{PO}_{4}$ translatory vibrations [22]. The peak at $181 \mathrm{~cm}^{-1}$ can be assigned to the $\mathrm{H}_{2} \mathrm{PO}_{4}$ rotational band [21] . The strongest peak at $914 \mathrm{~cm}^{-1}$ can be assigned to $\mathrm{PO}_{4}$ totally symmetric stretching mode [23]. In this experiment, no apparent shifting of all the modes was observed with change in laser conditioning parameters. No other alteration in the intensity change of the $914 \mathrm{~cm}^{-1}$ mode which is attributed to

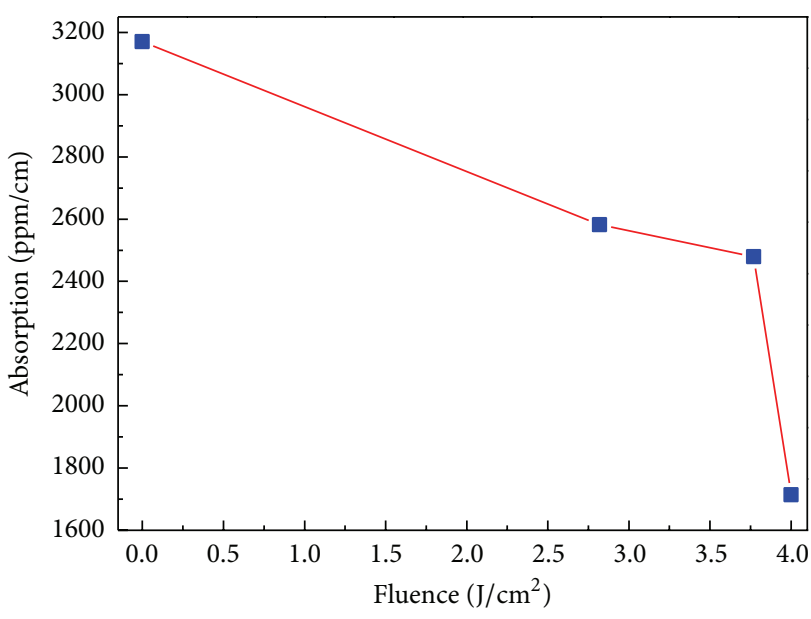

FIGURE 4: Photothermal absorption measurement of KDP crystal.

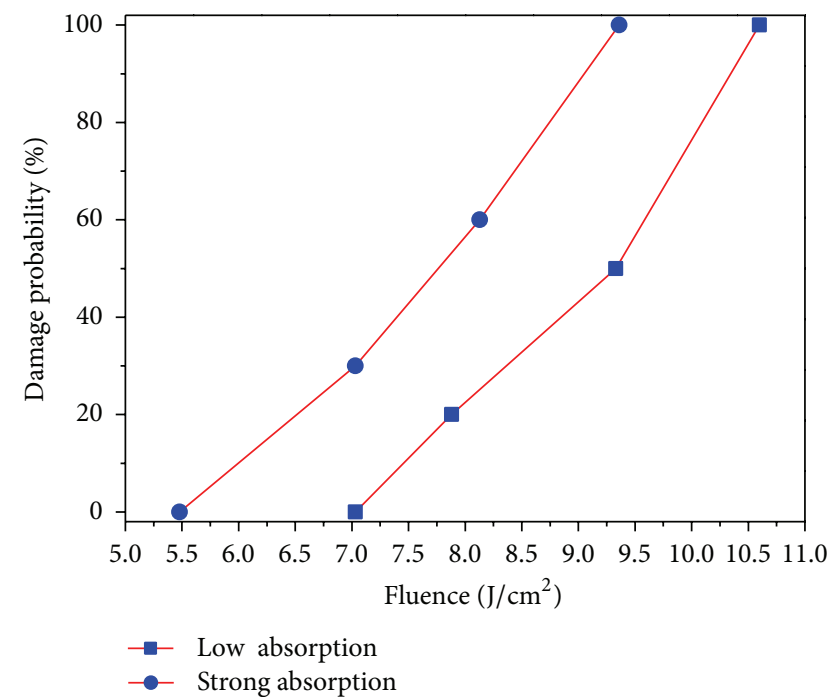

FIgURE 5: 1-on-1 test of the KDP for two absorbing areas.

the totally symmetric stretching model of $\mathrm{PO}_{4}$ tetrahedra is observed in Figures 6(b) and 6(c) compared to Figure 6(a). The intensity of the $914 \mathrm{~cm}^{-1}$ mode of conditioned crystal by the changing of laser fluence is lower than pristine crystal. Compared with pure KDP, the intensity of less than $300 \mathrm{~cm}^{-1}$ mode of laser conditioned crystals is decreased in all cases. The decrease of the intensity of all the modes may be attributed to the following possibilities: (1) depolarization of the Raman scattering light causing change of spectra, because depolarization will lower the intensity of all A1 modes [23], (2) the rotation of the crystal axes causing change of the Raman spectrum (the intensity of all the modes decreases for the spectra by changing the angle of crystal axes from $50^{\circ}$ to $90^{\circ}$ [24]), and (3) decrease of the absorption associated with the $\mathrm{PO}_{4}$ molecule causing decrease of Raman spectrum [23]. For the $914 \mathrm{~cm}^{-1}$ mode, changing of its intensity merely occurs at different conditioning fluence operation. And the effectiveness of laser conditioning relies mainly 
TABLE 1: Assignment of Raman active mode frequencies of KDP at $300 \mathrm{~K}$.

\begin{tabular}{lcccc}
\hline Mode & This work & Serra et al. [19] & Agrawal and Perry [20] & Assignment [21] \\
\hline A1 & 356 & 363.9 & 360 & $\delta_{s}\left[\mathrm{PO}_{2}, \mathrm{P}(\mathrm{OH})_{2}\right]$ \\
A1 & 914 & 916.9 & 918 & $v_{s} \mathrm{P}(\mathrm{OH})_{2}$ \\
B1 & 475 & 474.5 & 479 & $\delta_{r}\left[\mathrm{PO}_{2}, \mathrm{P}(\mathrm{OH})_{2}\right]$ \\
B1 & 557 & 564.1 & 570 & $\delta_{\text {sc }}\left[\mathrm{PO}{ }_{2}, \mathrm{P}(\mathrm{OH})_{2}\right]$ \\
B2 & 181 & 179.5 & 174 & Lattice vibrations \\
B2 & 391 & 394 & 386 & $\gamma_{\tau} \mathrm{P}(\mathrm{OH})_{2}$ \\
E & 114 & 114 & 113 & Lattice vibrations \\
\hline
\end{tabular}

$v_{\mathrm{s}}$ : very strong, $\mathrm{s}$ : strong, $\mathrm{m}$ : medium, and $\mathrm{w}$ : weak.

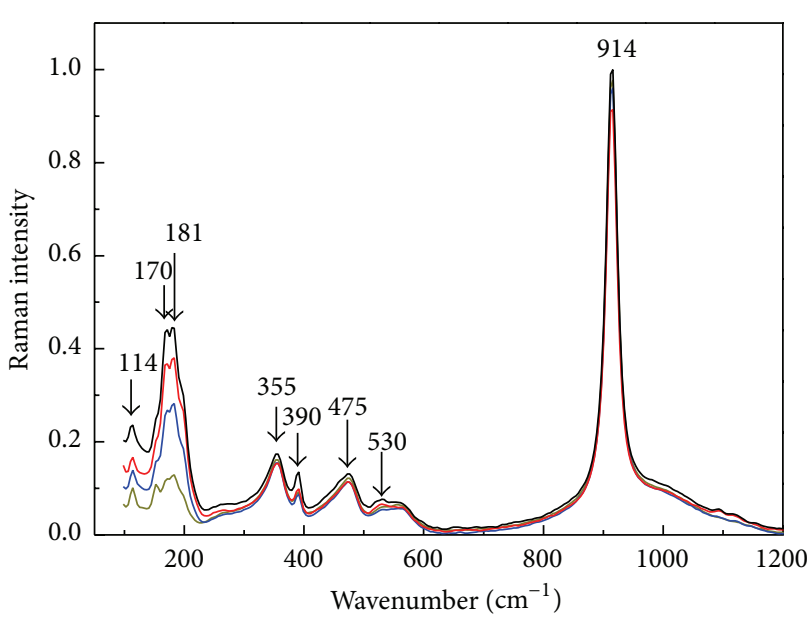

Preexposuree fluence

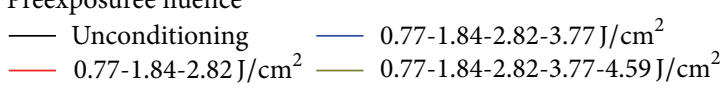

(a)

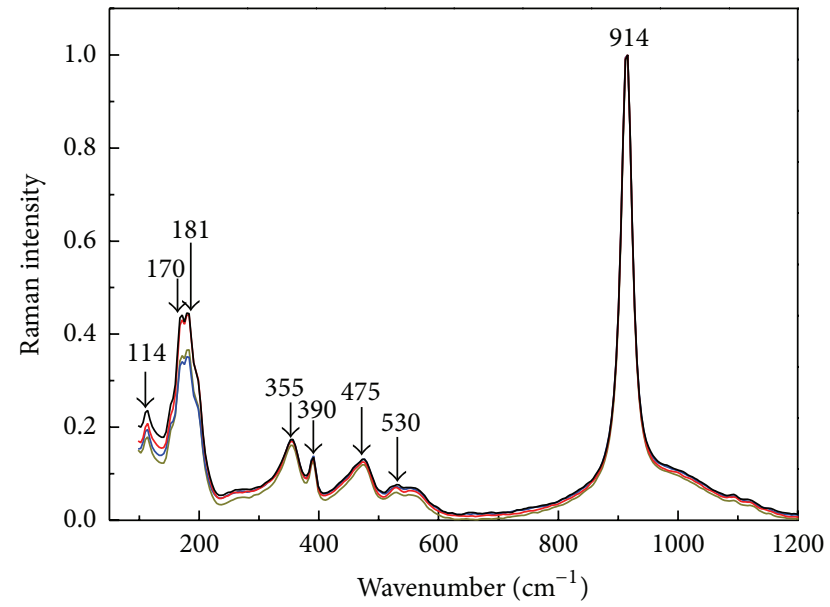

Pre-exposure scan numbre (fluence is $0.77-1.84-2.82-3.77-4.59 \mathrm{~J} / \mathrm{cm}^{2}$ )

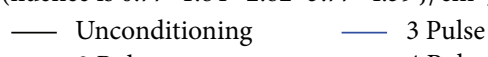

- 2 Pulse

4 Pulse

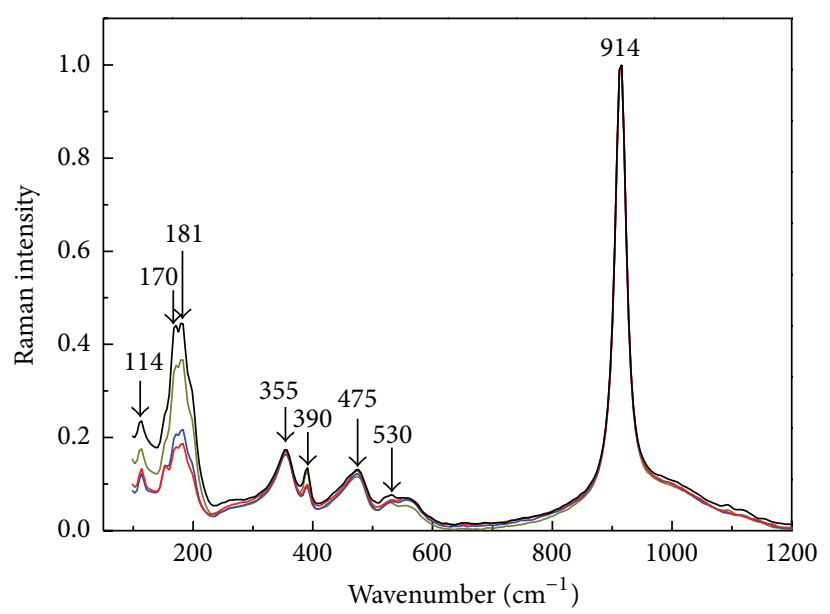

Pre-exposure fluence step

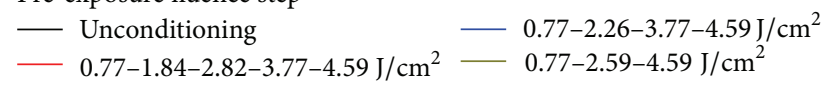

(c)

FIGURE 6: Comparison of Raman spectra obtained by multiparametric conditions: (a) laser fluence; (b) pulse number; (c) fluence step. 
on the conditioning fluence. This result strongly indicates that the effectiveness of laser conditioning is associated with the individual mode of $\mathrm{PO}_{4}$ molecule. Therefore, in the laser conditioning process, the low laser fluence cannot cause severe vibration and a subsequent distortion of the $\mathrm{PO}_{4}$ tetrahedra [25]. For the modes located at 114, 170, and $181 \mathrm{~cm}^{-1}$, variation on intensity may be attributed to the decrease of the absorption due to recombination of electrondefects or release of lattice stress causing change of these modes under subdamage threshold laser irradiation. And there is no structural phase transition because the mode at $181 \mathrm{~cm}^{-1}$ did not show an anomalous behavior in the laser conditioning process [19]. These modes are also associated with $\mathrm{PO}_{4}$ tetrahedra, and then these changes suggest that the effectiveness of laser conditioning is associated with the small deformation of the $\mathrm{PO}_{4}$ tetrahedral units.

\section{Conclusion}

In order to better understand the process of laser scanconditioning for KDP crystal, the structure properties of KDP crystals are investigated using photothermal absorption and Raman spectra by various laser conditioning parameters. The change of photothermal absorption is related to laser conditioning fluence. In the process of laser conditioning, Raman spectra show a decrease of the intensity of $914 \mathrm{~cm}^{-1}$ mode and less than $300 \mathrm{~cm}^{-1}$ mode. This result suggests that the effectiveness of laser conditioning may be associated with the individual mode of $\mathrm{PO}_{4}$ molecule.

\section{Conflict of Interests}

The authors declare that there is no conflict of interests regarding the publication of this paper.

\section{Acknowledgments}

This work was performed under the auspices of the Science Foundation of China Academy of Engineering Physics, China (Grant no. 2011B0401065), the National Natural Science Foundation of China (61178018 and 61078075), the Ph.D. Funding Support Program of Education Ministry of China (20110185110007), and the Laboratory of Precision Manufacturing Technology.

\section{References}

[1] J. J. De Yoreo, A. K. Burnham, and P. K. Whitman, "Developing $\mathrm{KH}_{2} \mathrm{PO}_{4}$ and $\mathrm{KD} 2 \mathrm{PO}_{4}$ crystals for the world's most powerful laser," International Materials Reviews, vol. 47, no. 3, pp. 113-152, 2002.

[2] L. J. Atherton, F. Rainer, J. J. De Yoreo, I. M. Thomas, N. P. Zaitseva, and F. P. De Marco, "Thermal and laser conditioning of production and rapid growth KDP and $\mathrm{KD}^{*} \mathrm{P}$ crystals," in LaserInduced Damage in Optical Materials, vol. 2114 of Proceedings of SPIE, pp. 36-45, 1993.

[3] M. Runkel, S. Maricle, R. Torres et al., "The effect of thermal annealing and second harmonic generation on bulk damage performance of rapid-growth KDP type I doublers at $1064 \mathrm{~nm}$," in Laser-Induced Damage in Optical Materials, J. Gregory, H. Arthur, Guenther et al., Eds., vol. 4347 of Proceedings of SPIE, pp. 389-399, October 2000.

[4] R. A. Negres, P. DeMange, and S. G. Demos, "Investigation of laser annealing parameters for optimal laser-damage performance in deuterated potassium dihydrogen phosphate," Optics Letters, vol. 30, no. 20, pp. 2766-2768, 2005.

[5] M. Runkel, K. Neeb, M. Staggs, J. Auerbach, and A. Burnham, "The results of raster-scan laser conditioning studies on DKDP triplers using Nd:YAG and excimer lasers," in Laser-Induced Damage in Optical Materials, J. Gregory, H. Arthur, Guenther et al., Eds., vol. 4679 of Proceedings of SPIE, pp. 368-383, October 2001.

[6] D. Damiani, H. Piombini, D. Plessis, T. Donval, L. Lamaignere, and M. LoiseauG. J. Exarhos, A. H. Guenther, K. L. Lewis, M. J. Soileau, and C. J. Stolz, "Excimer laser conditioning of KDP: influence of the laser parameters and crystal orientation on the laser damage threshold," in Laser-Induced Damage in Optical Materials, vol. 5647 of Proceedings of SPIE, pp. 290-297, September 2004.

[7] J. J. Adams, T. L. Weiland, J. R. Stanley et al., "Pulse length dependence of laser conditioning and bulk damage in $\mathrm{KD}_{2} \mathrm{PO}_{4}$," in Laser-Induced Damage in Optical Materials, G. J. Exarhos, A. H. Guenther, K. L. Lewis, M. J. Soileau, and C. J. Stolz, Eds., vol. 5647 of Proceedings of SPIE, pp. 265-278, September 2004.

[8] A. K. Burnham, M. Runkel, M. D. Feit et al., "Laserinduced damage in deuterated potassium dihydrogen phosphate," Applied Optics, vol. 42, no. 27, pp. 5483-5495, 2003.

[9] P. Demange, C. W. Carr, R. A. Negres, H. B. Radousky, and S. G. Demos, "Multiwavelength investigation of laser-damage performance in potassium dihydrogen phosphate after laser annealing," Optics Letters, vol. 30, no. 3, pp. 221-223, 2005.

[10] P. DeMange, C. W. Carr, R. A. Negres, H. B. Radousky, and S. G. Demos, "Multi-wavelength investigation of laser-damage performance in KDP and DKDP following laser annealing," Optics Letters, vol. 30, no. 3, 2004, UCRL-JRNL-206405.

[11] M. D. Feit and A. M. Rubenchik, "Implications of nanoabsorber initiators for damage probability curves, pulselength scaling and laser conditioning," in Laser-Induced Damage in Optical Materials, vol. 5273 of Proceedings of SPIE, pp. 74-82, September 2003.

[12] C. W. Carr, H. B. Radousky, and S. G. Demos, "Wavelength dependence of laser-induced damage: determining the damage initiation mechanisms," Physical Review Letters, vol. 91, no. 12, pp. 7402-7406, 2003.

[13] P. DeMange, R. A. Negres, C. W. Carr, H. B. Radousky, and S. G. Demos, "A multi-dimensional investigation of laser conditioning in KDP and DKDP crystals," in Laser-Induced Damage in Optical Materials, vol. 5991 of Proceedings of SPIE, September 2005.

[14] C. D. Marshall, S. A. Payne, M. A. Henesian, J. A. Speth, and H. T. Powell, "Ultraviolet-induced transient absorption in potassium dihydrogen phosphate and its influence on frequency conversion," Journal of the Optical Society of America B, vol. 11, no. 5, pp. 774-785, 1994.

[15] B. W. Woods, M. J. Runkel, M. Yan et al., "Investigation of damage in KDP using light scattering techniques," in LaserInduced Damage in Optical Materials, H. E. Bennett, A. H. Guenther, M. R. Kozlowski, B. E. Newnam, and M. J. Soileau, Eds., vol. 2966 of Proceedings of SPIE, pp. 20-31, usa, October 1996. 
[16] D. Damiani, H. Piombini, and D. Plessis, "Excimer laser conditioning of KDP: correlation of non-destructive optical diagnostics at $351 \mathrm{~nm}$ with laser damage threshold," in LaserInduced Damage in Optical Materials, G. J. Exarhos, A. H. Guenther, K. L. Lewis, M. J. Soileau, and C. J. Stolz, Eds., vol. 5647 of Proceedings of SPIE, pp. 540-549, September 2004.

[17] G. Duchateaua, "Modeling laser conditioning of KDP crystals," in Laser-Induced Damage in Optical Materials, G. J. Exarhos, V. E. Gruzdev, D. Ristau, M. J. Soileau, and C. J. Stolz, Eds., vol. 7504 of Proceedings of SPIE, pp. 75041k1-7504113, 2009.

[18] H. Bercegol, P. Grua, D. Hébert, and J.-P. Morreeuw, "Progress in the understanding of fracture related laser damage of fused silica," in Laser-Induced Damage in Optical Materials, vol. 6720 of Proceedings of SPIE, September 2007.

[19] K. C. Serra, F. E. A. Melo, J. M. Filho, F. A. Germano, and J. E. Moreira, "Raman study of the tetragonal $\rightarrow$ monoclinic phase transition in KDP," Solid State Communications, vol. 66, no. 6, pp. 575-579, 1988.

[20] D. K. Agrawal and C. H. Perry, "The temperature dependent Raman spectra of KDP, KD*, KDA and ADP," in Proceedings of the 2nd Conference on Light Scattering in Solids, p. 429, 1971.

[21] H. Ettoumi, Y. Gao, M. Toumi, and T. Mhiri, "Thermal analysis, Raman spectroscopy and complex impedance analysis of $\mathrm{Cu}^{2+}$ doped KDP," Ionics, vol. 19, no. 7, pp. 1067-1075, 2013.

[22] T. Som, M. S. Navati, and V. N. Kulkarni, "Physico-chemical changes in ion-irradiated KDP," Nuclear Instruments and Methods in Physics Research B: Beam Interactions with Materials and Atoms, vol. 179, no. 4, pp. 551-556, 2001.

[23] S. G. Demos, M. Yan, M. Staggs, J. J. De Yoreo, and H. B. Radousky, "Raman scattering investigation of $\mathrm{KH}_{2} \mathrm{PO}_{4}$ subsequent to high fluence laser irradiation," Applied Physics Letters, vol. 72, no. 19, pp. 2367-2369, 1998.

[24] M. K. Srivastava and C. H. Wang, "Breakdown of selection rules in the Raman spectra of KDP," The Journal of Chemical Physics, vol. 62, no. 9, pp. 3439-3441, 1975.

[25] R. A. Negres, S. O. Kucheyev, P. DeMange et al., "Decomposition of $\mathrm{KH}_{2} \mathrm{PO}_{4}$ crystals during laser-induced breakdown," Applied Physics Letters, vol. 86, no. 17, Article ID 171107, pp. 1-3, 2005. 

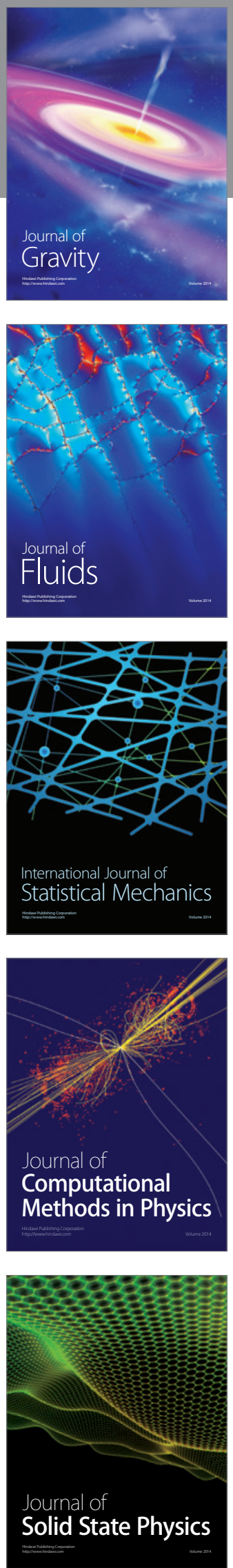

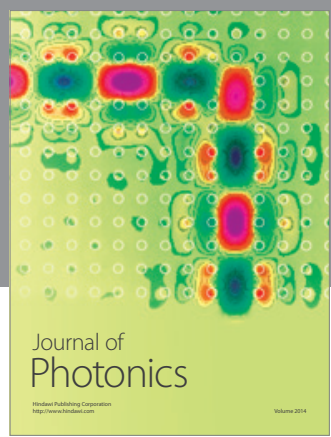

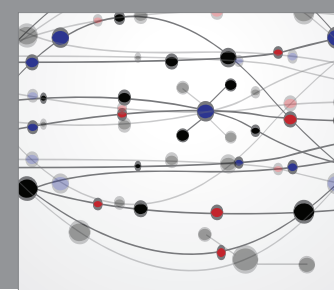

The Scientific World Journal

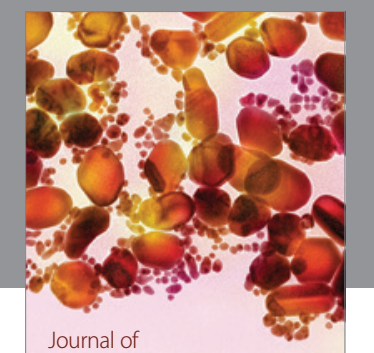

Soft Matter
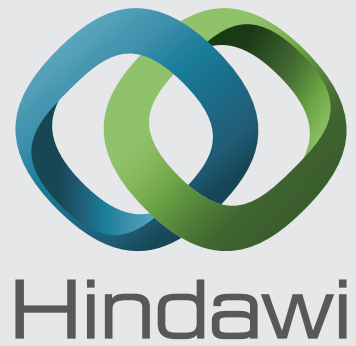

Submit your manuscripts at

http://www.hindawi.com
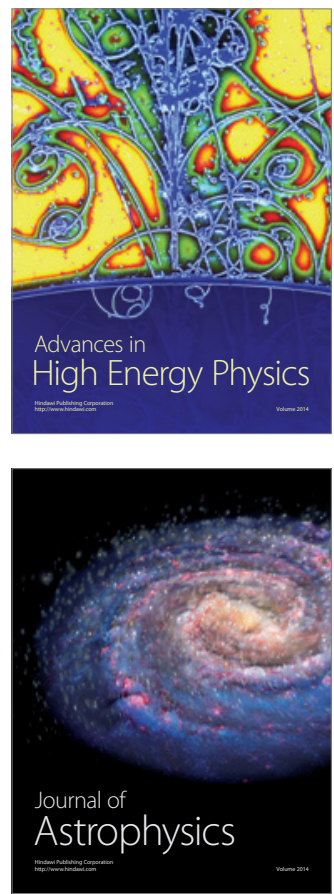
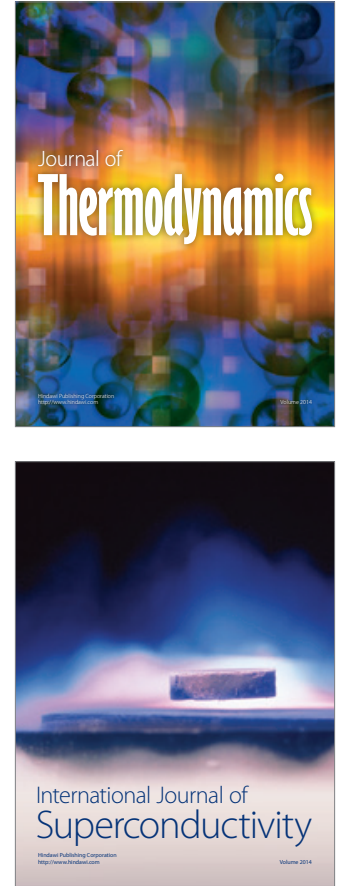
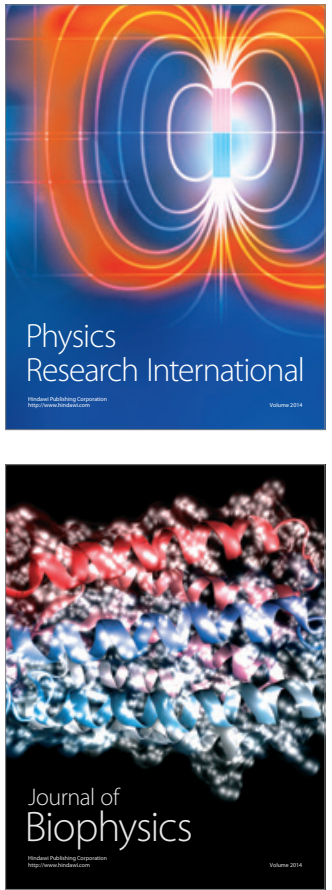
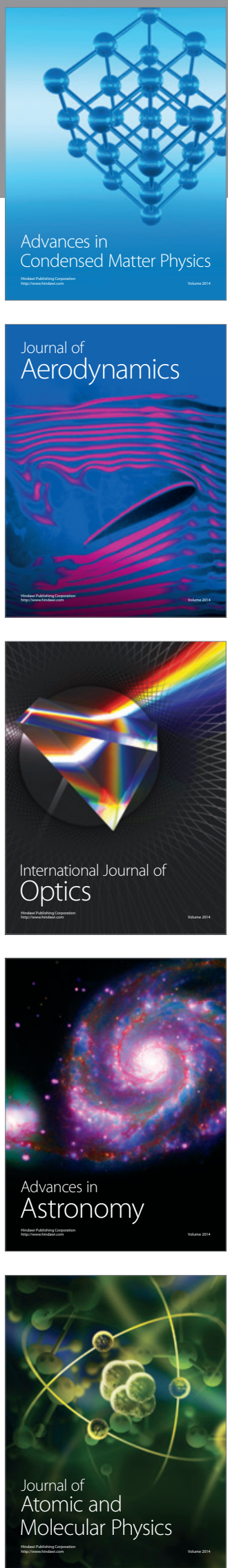